\title{
Periodontal Healing Following Guided Tissue Regeneration With Citric Acid and Fibronectin Application
}

\author{
Raul G. Caffesse, ${ }^{*}$ Carlos E. Nasjleti, * Gissela B. Anderson, ${ }^{*}$ Dennis E. Lopatin, ${ }^{+}$ \\ Billy A. Smith, ${ }^{+}$and Edith C. Morrison*
}

THIS STUDY WAS UNDERTAKEN TO DETERMINE the effects of guided tissue regeneration (GTR) with and without citric acid conditioning and autologous fibronectin application. The study subjects were four female beagle dogs with spontaneous periodontitis. The dogs were given thorough root debridement and 4 weeks later, mucoperiosteal flaps were raised on both sides of the mandible involving the $2 \mathrm{nd}, 3 \mathrm{rd}$, and 4th premolar and 1st molar teeth. After debridement, notches were placed on the roots at the level of supporting bone. Citric acid ( $\mathrm{pH} 1)$ was topically applied for 3 minutes on the exposed root surfaces of one side (experimental). The roots were irrigated with normal saline solution. Both the root surfaces and the inner surface of the flap were then bathed in autologous fibronectin in saline. Following this, Gore-Tex periodontal material was adapted to the roots of each tooth and sutured. The contralateral side, serving as control, was treated by surgery and application of Gore-Tex periodontal material only. All membranes were removed 1 month after surgery, and the dogs sacrificed at 3 months. Both mesio-distal and bucco-lingual microscopic histological sections were evaluated by descriptive histology, and linear measurements and surface area determination of the furcal tissues were made. Periodontal healing following the use of GTR procedure resulted in an increase in connective tissue and alveolar bone regeneration. Adjunctive citric acid plus autologous fibronectin produced slightly better results, but these differences were not statistically significant for this sample. J Periodontol 1991;62:21-29.

Key Words: Guided tissue regeneration; citric acid; fibronectin; periodontitis therapy.

The ultimate goal of periodontal therapy includes not only the arrest of progressive periodontal disease but also the predictable regeneration of the periodontium at the site of previous peridontal breakdown; i.e., the formation of new cementum, new periodontal ligament, and new alveolar bone. ${ }^{1-3}$ The evidence available to date indicates that the most frequent mode of wound healing following surgical therapy is the development of a long junctional epithelium and connective tissue adhesion, ${ }^{4-9}$ which may give a good clinical result ${ }^{10-15}$ but fails to satisfy the goal of regeneration. In order for regeneration to occur, periodontal ligament fibers must be embedded in cementum that has formed on a previously diseased or denuded root surface..$^{1-3}$

In a previous report, ${ }^{16}$ improvement in new connective tissue attachment to root surfaces of beagle dogs affected with natural periodontitis occurred when the teeth were surgically treated using a modified Widman flap approach; the

*Department of Periodontics, Dental Branch, The University of Texas Health Science Center at Houston, TX.

'The University of Michigan School of Dentistry, Ann Arbor, MI. roots were demineralized with citric acid and fibronectin was applied on the inner flap surface and on the roots. Apparently, fibronectin, when used with citric acid, enhanced the regeneration of connective tissue attachment, possibly by increasing interactions between exposed root surface collagen and fibroblasts within the gingival connective tissue. ${ }^{16}$ More recently, in beagle dogs, Gore-Tex ${ }^{\ddagger}$ periodontal material was effective in blocking gingival epithelial downgrowth and connective tissue proliferation, promoting new attachment according to the principle of guided tissue regeneration. ${ }^{17,18}$ In humans, ${ }^{19-21}$ results showed that the formation of a connnective tissue attachment was considerably favored by the placement of Gore-Tex membranes which prevented the gingival epithelium and the gingival connective tissue from interfering with healing. Clinical measurements demonstrated decreased probing depth and gains in attachment levels for treated furcations and vertical defects. Biopsies of treated sites revealed new cementum

*W.L. Gore and Associates, Flagstaff, AZ. 
with inserting connective tissue fibers and varying amounts of bone. ${ }^{19}$

The purpose of this histologic and histometric study was to evaluate in beagle dogs the healing following the use of combined techniques of epithelial and gingival flap exclusion via Gore-Tex periodontal material coupled with citric acid root demineralization plus autologous fibronectin application which may afford significant advantage over either technique alone.

\section{MATERIALS AND METHODS}

Four purebred female beagle dogs 6 to 8 years old with naturally occurring periodontal disease were used in this study and maintained on a hard diet, except for the 2 weeks following surgery when a soft diet was used. The dogs were subjected to a thorough intraoral examination which included periodontal probing and intraoral radiographs. The teeth were scaled and subsequently polished. Plaque control was maintained by topical application of a $0.12 \%$ solution of chlorhexidine gluconate, 3 times weekly. Surgical wounding of the animals started 4 weeks after scaling and root planing.

\section{Surgical Procedures}

Prior to surgery, each dog was sedated with I.V. Ketamine $\mathrm{HCl}, 25 \mathrm{mg} / \mathrm{ml}$, followed by sodium phenobarbital anesthesia, $35 \mathrm{mg} / \mathrm{kg}$. The area to receive surgery was locally anesthetized with $2 \%$ Xylocaine containing epinephrine $(1: 50,000)$ to reduce hemorrhage and ensure profound anesthesia. Two mandibular quadrants in each dog were treated. Each quadrant included the 2nd, 3rd, and 4th premolars and the 1st molar teeth. Reverse bevel mucoperiosteal flaps were raised. Following the elevation of soft tissue flaps, the exposed root surfaces were carefully planed. Reference notches, at the alveolar bone level, were positioned on the buccal aspect of the roots and extended interproximally and into the furcation areas. Following the placement of the notches, the sites were thoroughly flushed with sterile saline and blotted dry with a sterile gauze sponge. The roots of the teeth in one of these mandibular quadrants were demineralized for 3 minutes with a saturated solution of citric acid, $\mathrm{pH}$ 1. The site was thoroughly flushed with sterile saline solution. Autologous fibronectin in saline, $500 \mu \mathrm{gm} / \mathrm{ml}$, was applied to the surgical site. Both the root surfaces and the inner surface of the flap were bathed with the solution for 5 minutes while the excess was absorbed with sterile gauze. The quadrant was kept saliva free for a minimum of 30 minutes after its placement. No post-treatment irrigation of the surgical site receiving fibronectin was carried out. At this time, all teeth involved received the Gore-Tex periodontal material. The premolars and first molar of the contralateral quadrant were treated with guided tissue regeneration (GTR) procedure only. The periodontal material was placed so that 2 to $3 \mathrm{~mm}$ of crestal bone was covered and extended to the cementoenamel junction (CEJ). Once the material was in place, it was sutured using a suspensory suture around each tooth with a 4-0 Gore-Tex suture. Afterward, interproximal sutures were placed through the flaps assuring that they covered the periodontal material completely. Once suturing was completed, moderate pressure was applied over the sites for 4 to 5 minutes with a sterile gauze moistened with sterile saline, so as to minimize clot thickness and tissue gaping. Therefore, a split mouth design was obtained: test $=$ citric acid plus fibronectin plus Gore-Tex material, and control = Gore-Tex material only.

\section{Post-Surgical Procedures}

During the 2 weeks following surgery all dogs were fed a soft diet, and during the first week, toothbrushing was suspended in order to prevent unnecessary disruption of the Gore-Tex material and healing flaps.

Seven days after surgery, the dogs were anesthetized with $7.5 \%$ sodium thyamilal to allow for a rubber cup prophylaxis. In the following weeks, the surgical sites were maintained by brushing with a $0.12 \%$ chlorhexidine solution every other day. Four weeks after surgery, the Gore-Tex periodontal material was removed. Under general anesthesia, a split thickness flap procedure was performed and the tissues sutured back after material removal. Three months after surgery, the dogs were anesthetized as was done for surgery and final radiographs and photographs were taken. Following this, each dog was given additional anesthesia and sacrificed by exsanguination. The heads of the animals were perfused with $10 \%$ neutral buffered formalin and then refrigerated for 1 to 2 days. The jaws were dissected free, labeled and placed in formalin solution for further fixation.

\section{Laboratory Procedures}

In order to enhance the speed of demineralization, the jaws were further sectioned into one tooth blocks. Demineralization was accomplished with $10 \%$ tri-fluroacetic acid (TFA), the end point of which was determined radiographically. Following demineralization, the tissue specimens were washed, dehydrated, infiltrated, and embedded in paraffin and then sectioned at $6 \mu \mathrm{m}$ intervals. Twelve to 20 nonserial microscopic sections were made of each treated tooth, cut in the bucco-lingual direction, $30 \mu \mathrm{m}$ apart. Half of these sections were stained either with hematoxylin and eosin, Mallory's trichrome, or silver impregnation. Additionally, another group of 12 to 20 mesio-distal tissue sections were secured for surface area measurements of the furcations. These microscopic sections were examined under a binocular microscope and descriptive histologic and histometric evaluations were performed.

\section{Histologic Evaluation}

The descriptive histologic evaluation determined the presence or absence of root resorption and/or dentoalveolar ankylosis, the location of cementum formation, the direction of the periodontal fibers, and the degree of epithelial migration, as well as the degree of inflammation in the tissues. 


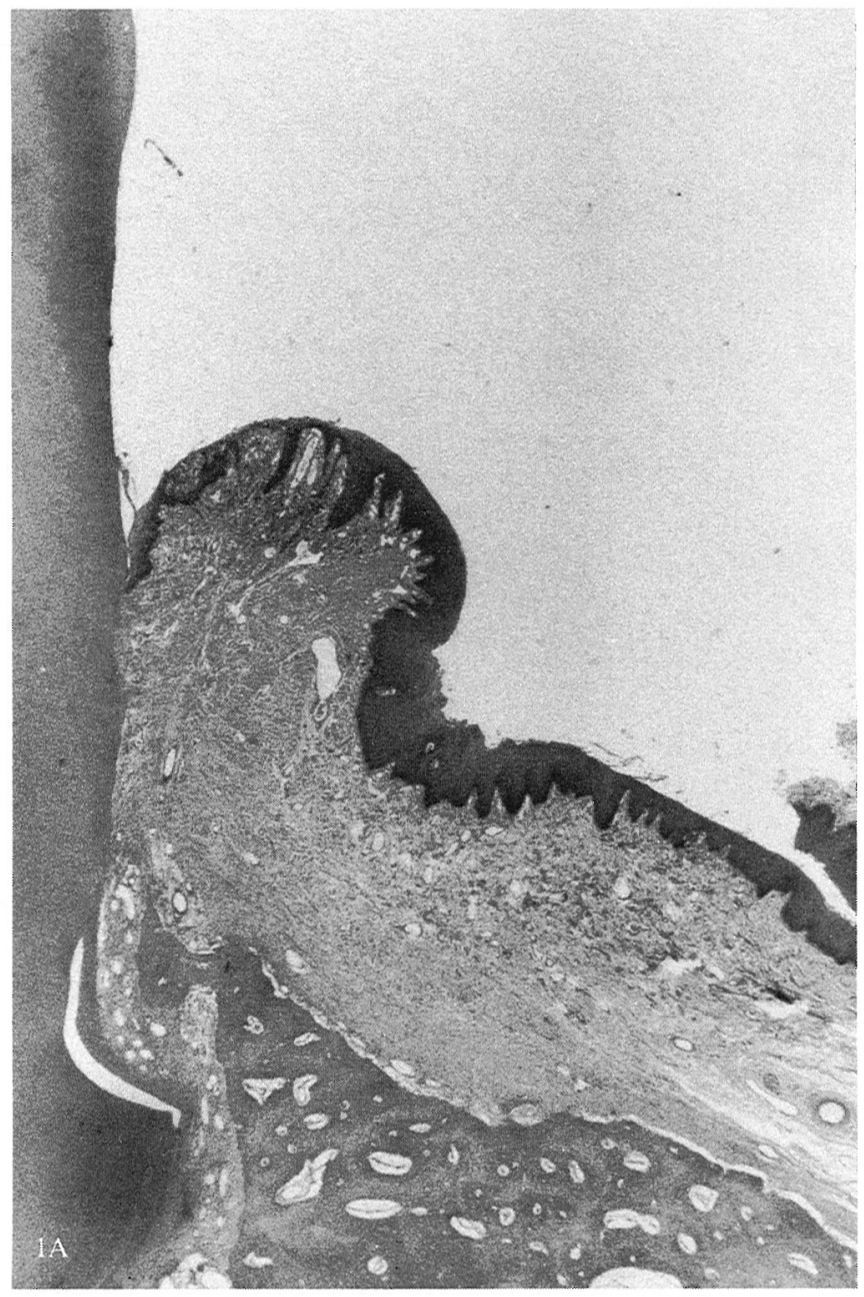

Figure 1A. Photomicrograph of representative bucco-lingual section showing periodontal healing following GTR procedure and citric acid + fibronectin application. (H\&E stain, original magnification $\times 25$ ).

\section{Histometric Evaluation}

Linear Measurements. Under the microscope and using the Filar's micrometer eye piece, tissue sections were measured by orienting the micrometer grid parallel to the shortest line which connected the apical extent of the root notch to the bone or cementum measured. ${ }^{21}$ The following measurements were performed: 1) from the root surface notch to the alveolar bone crest; 2) from the root surface notch to the apical extent of the junctional epithelium; 3) from the apical extent of the root notch to the coronal extent of the "newly deposited cementum," and 4) from the free gingival margin to the apical extent of the junctional epithelium.

Surface Area Determinations. In approximately 10 mesiodistal sections cut $30 \mu \mathrm{m}$ apart per tooth, including experimental and control teeth, surface area determinations (in $\mathrm{mm}^{2}$ ) relative to the furcations were made evaluating: 1) the whole interradicular space occupied by epithelium, connective tissue, cementum and bone; 2 ) the area filled with

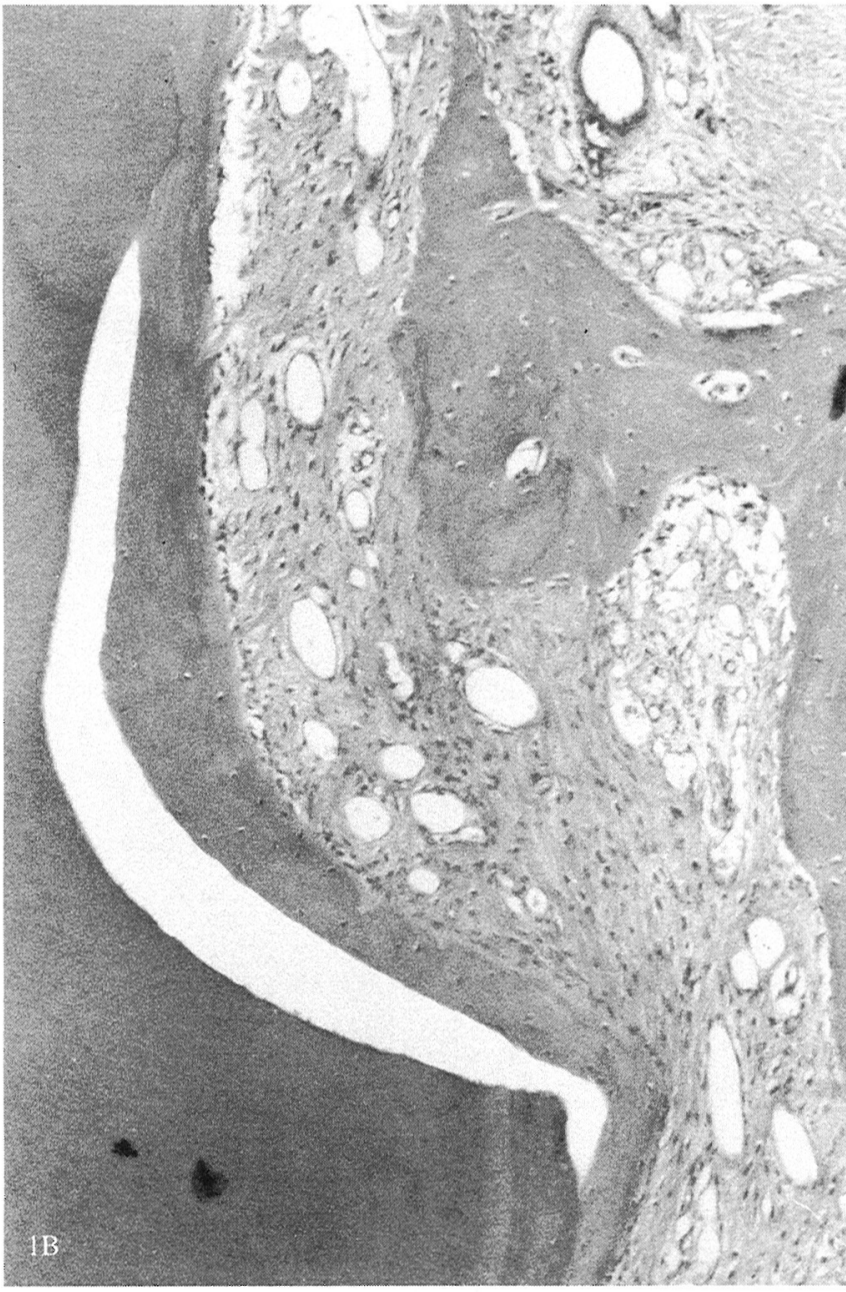

Figure 1B. Higher magnification of notch area seen in Figure $1 A$ showing new deposited cementum, regenerated alveolar bone, and new connective tissue attachment. (H\&E stain, original magnification $\times 100)$.

connective tissue plus cementum; 3) the area occupied by bone; and 4) the area occupied by epithelium. Images were digitized using the Zeiss image processing system attached to a microcomputer, as described previously. ${ }^{22}$

\section{Statistical Evaluation}

Mean values for the experimental and control quadrants, both linear and surface area measurements were statistically analyzed using paired $t$-tests $(\mathrm{N}=4)$.

\section{RESULTS}

\section{Histologic Observations}

The result of treatments after 3 months of healing is shown in Figures 1A through 1D. Experimental and control tissue specimens showed that there was no evidence of inflammatory cell infiltration interfering with healing. Although surface resorption lacunae were observed, they repaired and no areas of active resorption remained. Nor was there any 


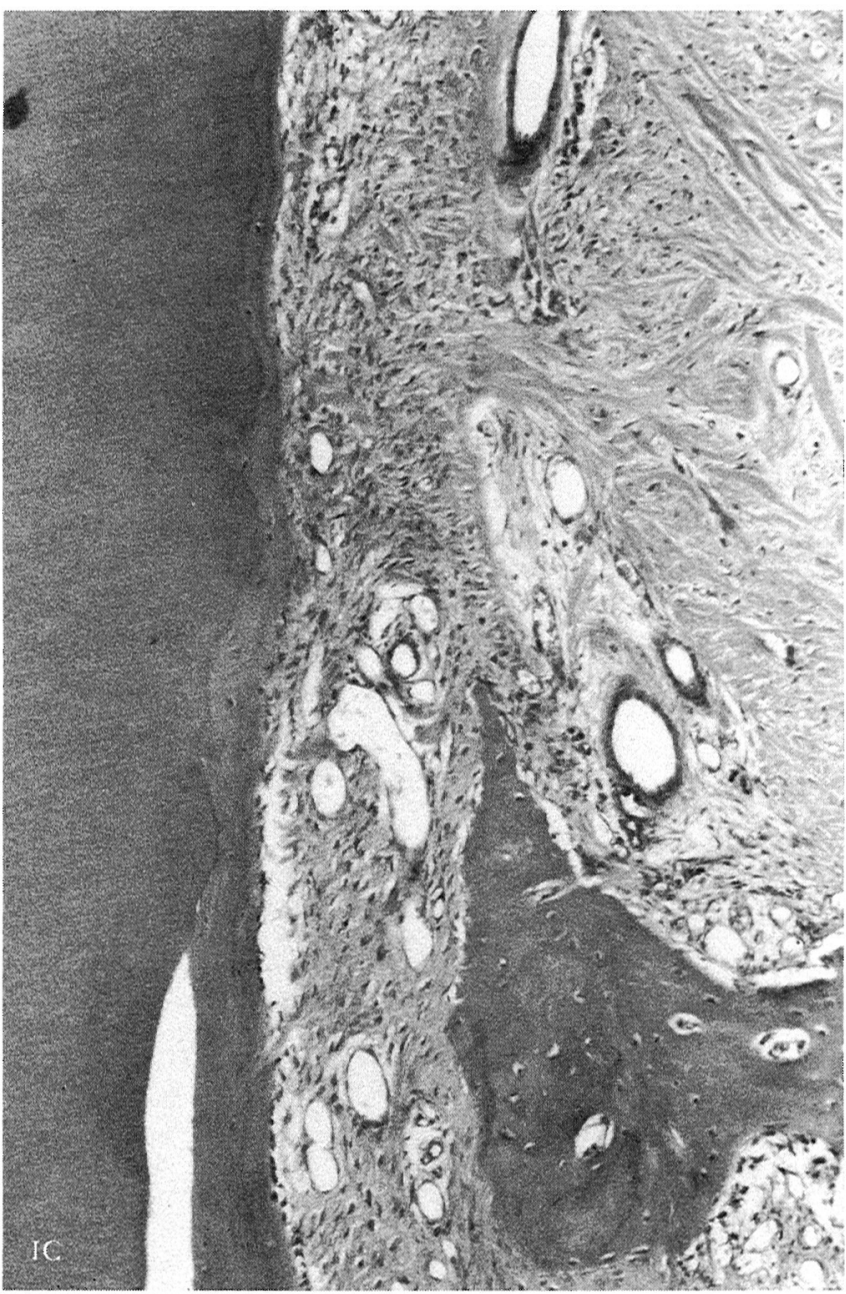

Figure 1C. Higher magnification of an area coronal to the root notch seen in Figure 1 A demonstrating repaired root surface resorption lacunae. $(H \& E$ stain, original magnification $\times 100)$.

indication that dentoalveolar ankylosis had occurred in the healing areas. A thin layer of newly deposited cementum was seen to cover the root surfaces. This newly formed cementum showed inclusions of cells. Considerable regeneration of alveolar bone has also taken place in these specimens. There was histologic evidence of new connective tissue attachment over the root surfaces. The majority of connective tissue fibers coronal to the apical extent of the root notch were oriented perpendicular or nearly perpendicular to the root surfaces, indicating functional orientation. In the furcations, regenerative connective tissue and bone was observed (Figs. 2A through 2C). Consistently, these tissues completely filled furcation areas above root surface reference notches. Often, epithelial proliferation was depicted in the coronal area of the furcation (Figs. 3A through 3D).

\section{Linear Measurements}

Table 1 shows the comparison of mean linear measurements in $\mathrm{mm}$ for the two treatment modalities by paired $t$-test.

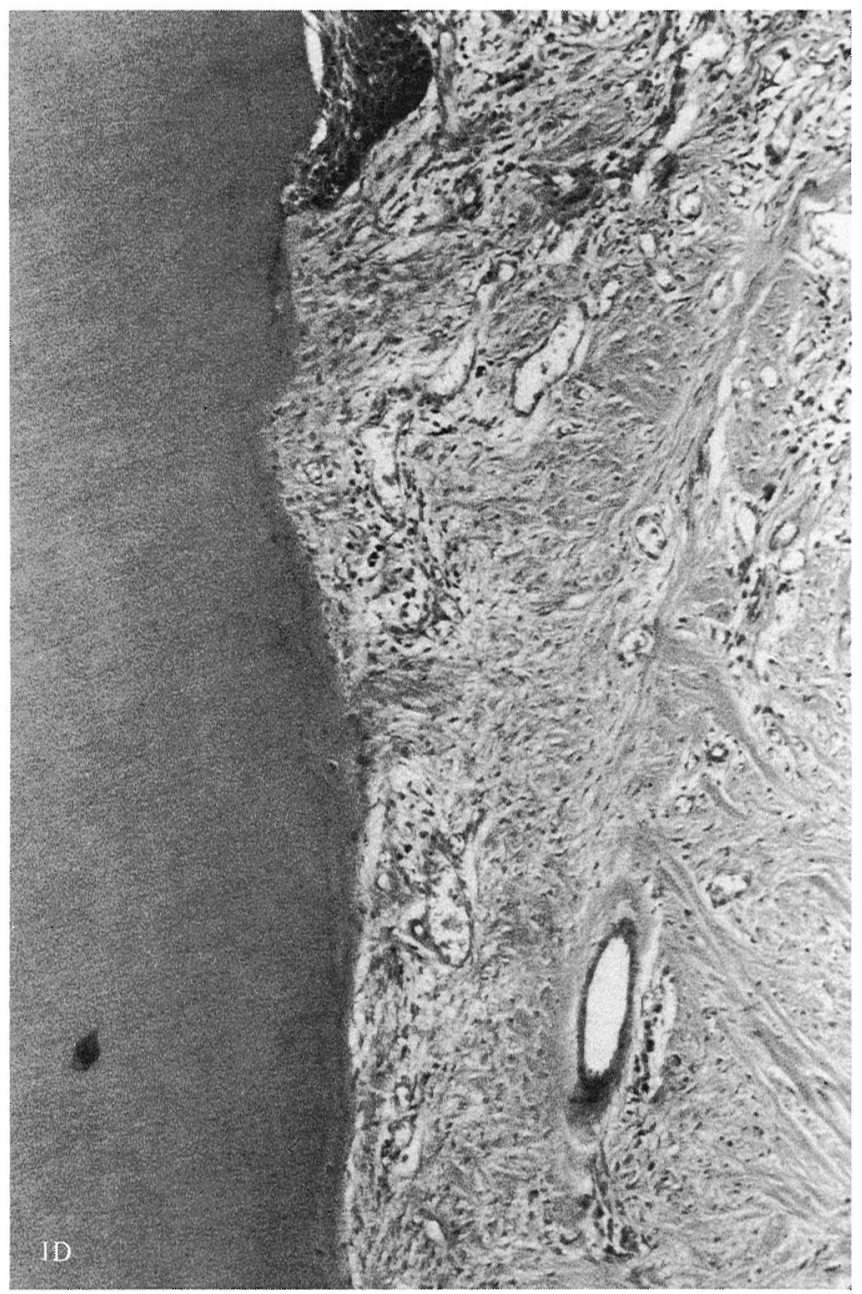

Figure 1D. Higher magnification of subgingival area seen in Figure $1 \mathrm{~A}$ showing that Gore-Tex periodontal material was effective in blocking gingival epithelial downgrowth and connective tissue proliferation, promoting new attachment according to the principle of GTR. (H\&E stain, original magnification $\times 100$ ).

Results showed no significant differences among the four linear measurements between the two treatments tested. However, slightly better results were obtained when citric acid and fibronectin were applied.

\section{Surface Area Determinations}

Table 2 shows the comparison of mean furcation fill measurements in $\mathrm{mm}^{2}$ for the treatment modalities by paired $t$ test. Results showed no significant differences between treatments among the four tissues measured. Nevertheless, the results of the area measurements indicated that, on the average, somewhat more new connective tissue, bone, and cementum were formed for the experimental than for the control specimens.

\section{DISCUSSION}

The results of this study have demonstrated that it is possible to favor the regeneration of a new connective tissue 


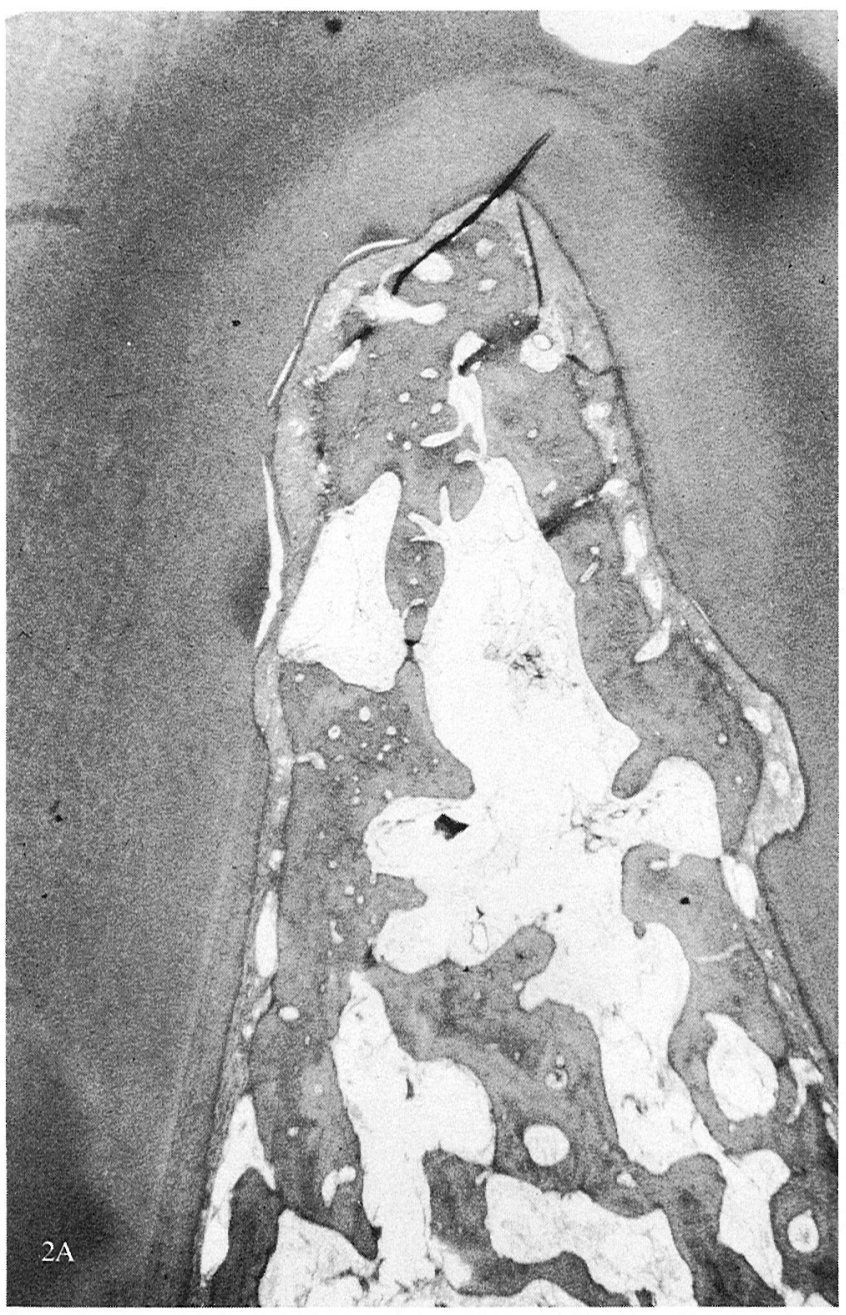

Figure 2A. Photomicrograph of representative mesio-distal section showing regenerative connective tissue and new alveolar bone filled completely furcation area following GTR and citric acid + fibronectin application. $(H \& E$ stain, original magnification $\times 25)$.

Table 1: Comparison of Mean Linear Measurements in $\mathrm{mm}$ for the 2 Treatment Modalities by Paired $t$-test $(N=4)$

\begin{tabular}{lcccccc}
\hline & Mean & Mean & Mean & \multicolumn{3}{c}{ Paired } \\
& Control & Experimental & Difference & SD & $t$-test & Significance \\
\hline Bone & -.30 & .23 & .53 & 1.20 & .88 & NS \\
Connective & & & & & & \\
$\quad$ Tissue & .78 & 1.28 & .50 & .61 & 1.61 & NS \\
Cementum & .59 & 1.04 & .45 & .46 & 1.97 & NS \\
Epithelium & 2.04 & 1.80 & .24 & .33 & 1.51 & NS \\
\hline
\end{tabular}

Degrees of freedom $=3.00$; NS $=$ not significant.

attachment to denuded root surfaces by a surgical procedure which is based on the principle of guided tissue regeneration. Also, coronal regeneration of alveolar bone as well as deposition of new cementum with inserting collagen fibers were observed in these specimens. These findings agree with many previous studies ${ }^{16-21,23-26}$ and support the concept that progenitor cells arising from the periodontal ligament, and possibly from bone, have the capacity to form

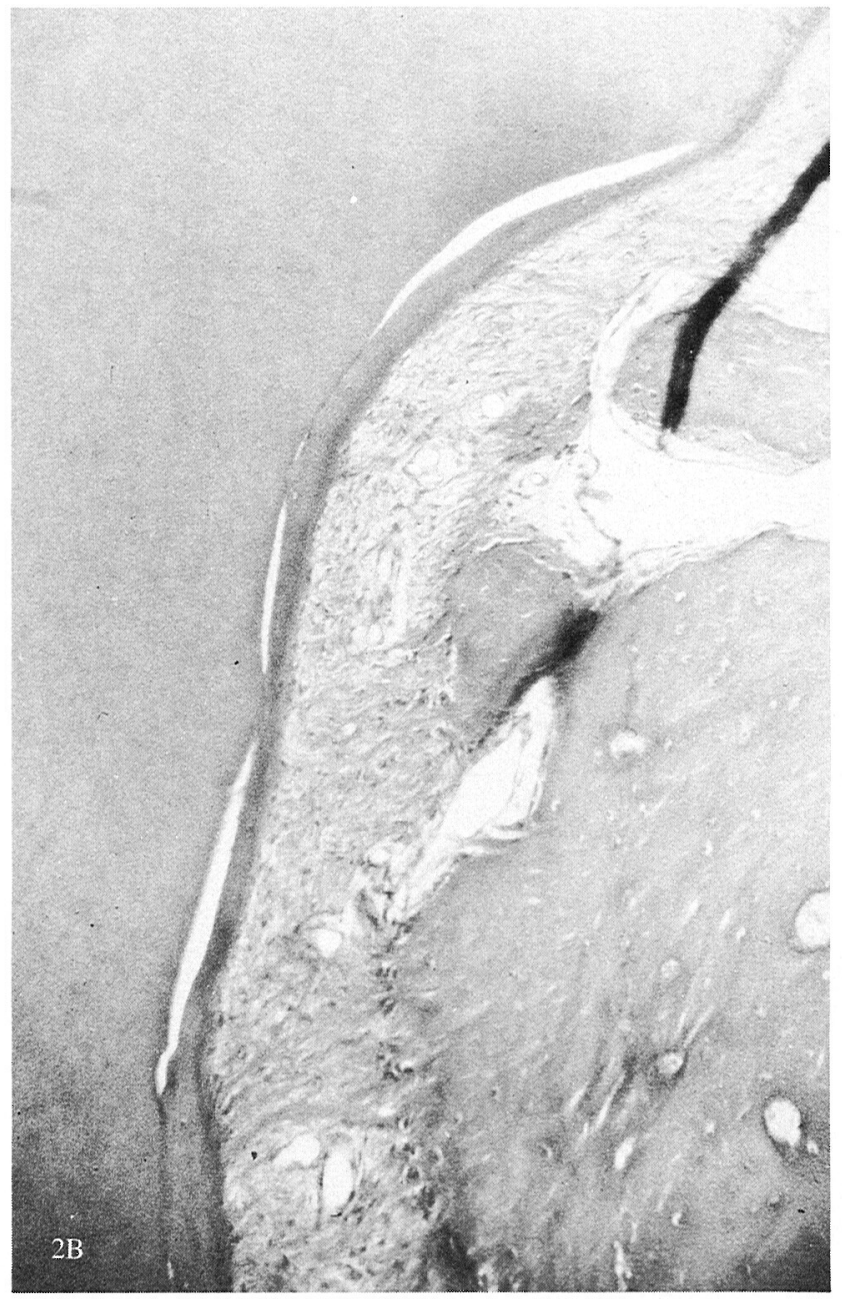

Figure 2B. Higher magnification of coronal area, above left notch, in Figure $2 A$ showing new deposited cementum, regenerated alveolar bone, and new connective tissue attachment. (H\&E stain, original magnification $\times 100)$.

new attachment. Partial regeneration of periodontal tissues was obtained when a "barrier" made of Millipore filter paper or Gore-Tex periodontal material was interposed between the gingival tissue on one side and the exposed root surfaces and the supporting alveolar bone on the other. The role of the barrier was two-fold: first, to prevent colonization of the exposed root surface by gingival cells; second, to allow selective repopulation of this surface by periodontal ligament cells.

Furthermore, several investigators ${ }^{27-32}$ have shown that the gingival epithelium, as well as the gingival connective tissue, can be excluded from healing after periodontal surgery by the use of biodegradable barriers. Blumenthal et al. ${ }^{27,28}$ used purified bovine collagen gel over bone grafted defects to inhibit epithelial migration into the defect. Magnusson et al. ${ }^{29}$ reported new attachment formation following controlled tissue regeneration using biodegradable polylactic acid membranes. Card et al. ${ }^{30}$ used Cargile, a 
Table 2: Furcation Fill Achieved in Beagle Dogs (in $\left.\mathrm{mm}^{2}\right)(\mathbf{N}=4)$

\begin{tabular}{lcccccc}
\hline & $\begin{array}{c}\text { Mean } \\
\text { Control }\end{array}$ & $\begin{array}{c}\text { Mean } \\
\text { Experimental }\end{array}$ & $\begin{array}{c}\text { Mean } \\
\text { Difference }\end{array}$ & SD & $\begin{array}{c}\text { Paired } \\
t \text {-test }\end{array}$ & Significance \\
\hline Ep + CT + C + B & 5.84 & 6.49 & .65 & 2.14 & .60 & NS \\
CT + C & 1.77 & 1.95 & .18 & .64 & .53 & NS \\
B & 3.89 & 4.30 & .41 & 1.42 & .57 & NS \\
Ep & .06 & .11 & .05 & .17 & .66 & NS \\
\hline
\end{tabular}

Ep = Epithelium; $\mathrm{CT}=$ Connective Tissue $\mathrm{C}=$ Cementum; $\mathrm{B}=$ Bone; $\mathrm{NS}=$ not significant.

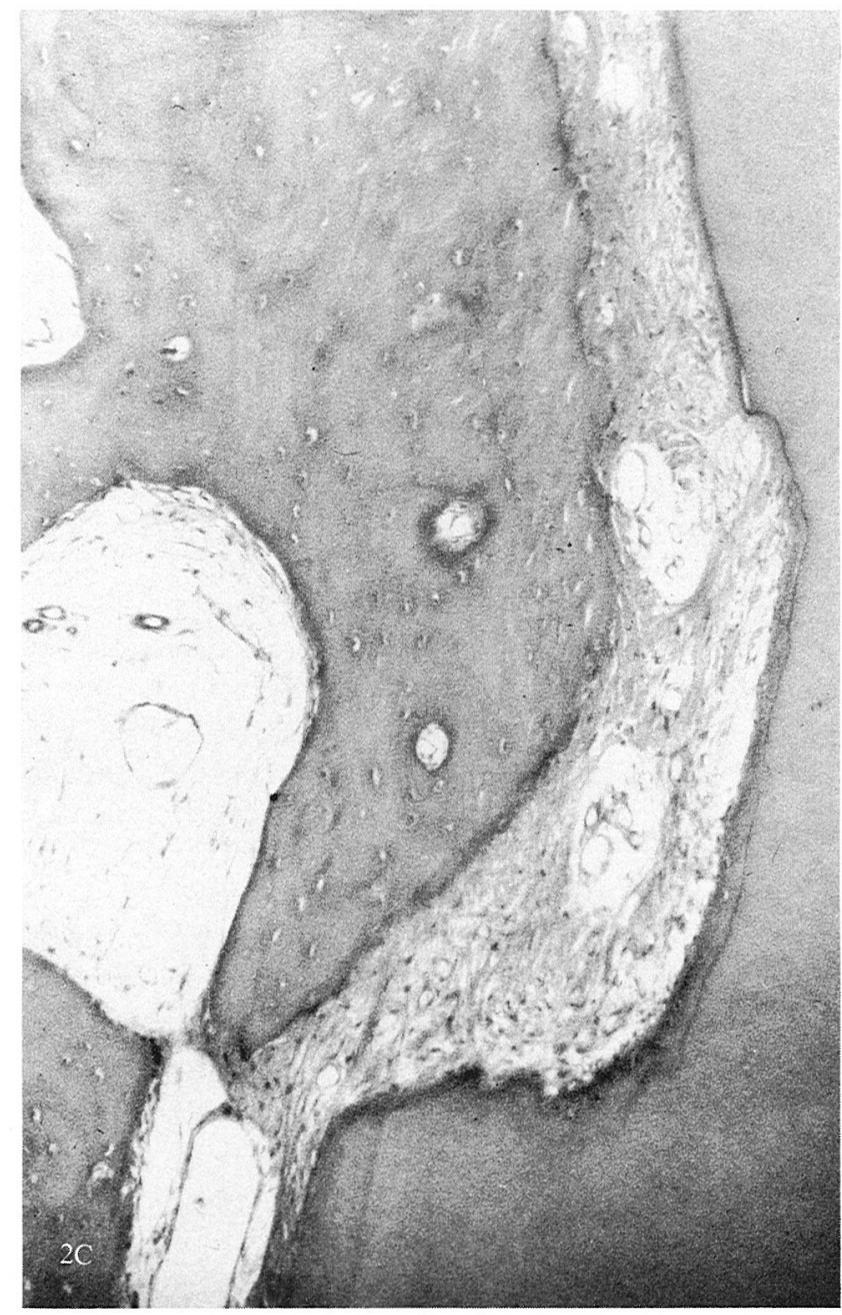

Figure $2 C$. Higher magnification of right notch area in Figure $2 A$ demonstrating new deposited cementum, newly formed alveolar bone, and repaired periodontal space. (H\&E stain, original magnification $\times 100)$.

resorbable membrane which is derived from the cecum of an ox, and reported that it could effectively divert gingival epithelium and connective tissue from involvement in the initial healing of root surfaces and thereby enhanced the formation of new attachment and bone. Pitaru et al. ${ }^{31,32}$ using collagen membranes, prevented apical migration of epithelium and supported new connective tissue attachment during periodontal wound healing. Results of all of these studies $^{16-21,23-32}$ indicated that the formation of new attach-

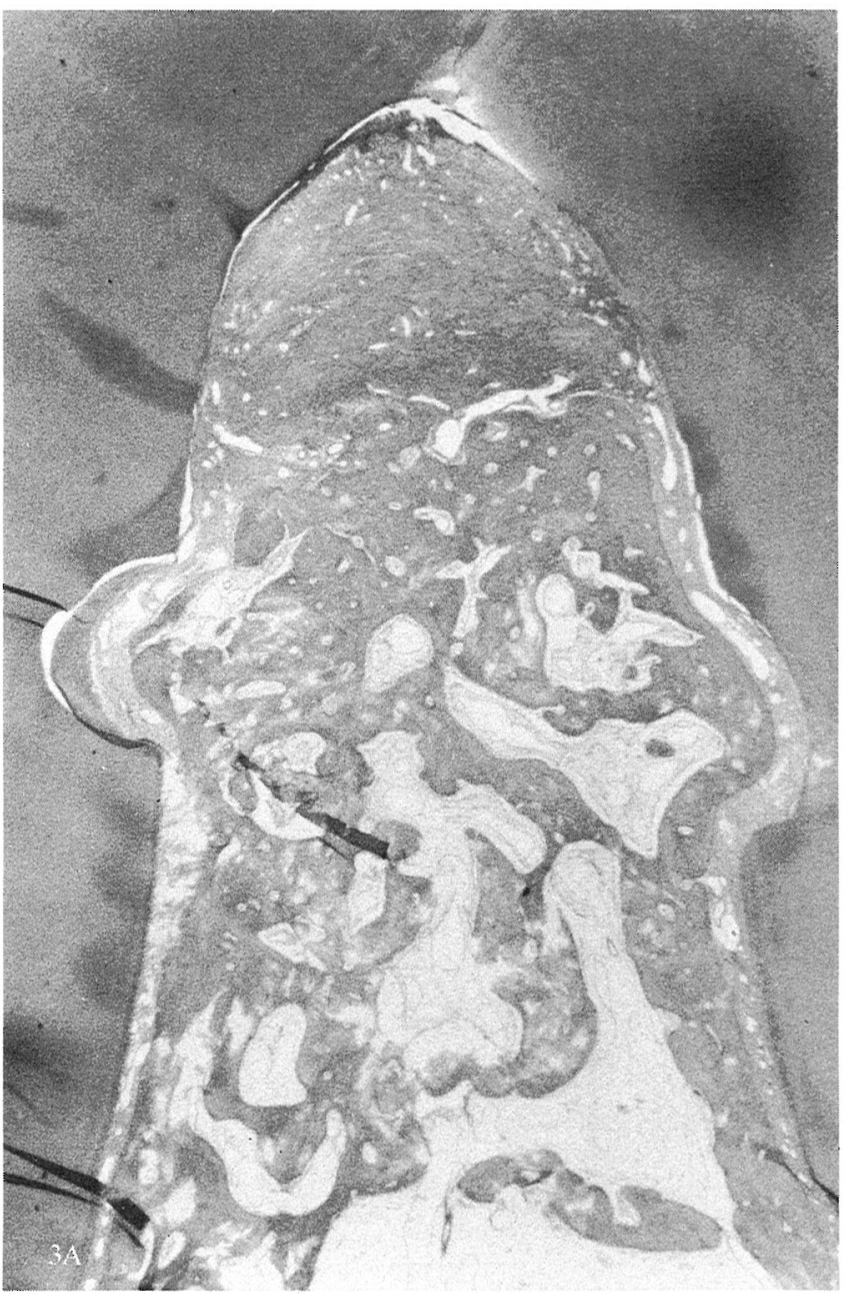

Figure 3A. Photomicrograph of representative mesio-distal section with partial epithelialization of the furcation. This tooth was treated with GoreTex periodontal material only. (H\&E stain, original magnification $\times 25)$.

ment is related to the problem of guiding the growth of granulation tissue in such a way that the root surface becomes repopulated by those specific cells which possess the biological capacity of regenerating the attachment apparatus.

The present study was designed to evaluate the healing response in beagle dogs following the use of combined procedures of epithelium and gingival flap exclusion via Gore-Tex periodontal material coupled with citric acid demineralization plus autologous fibronectin application which could afford significant advantage over either procedure 


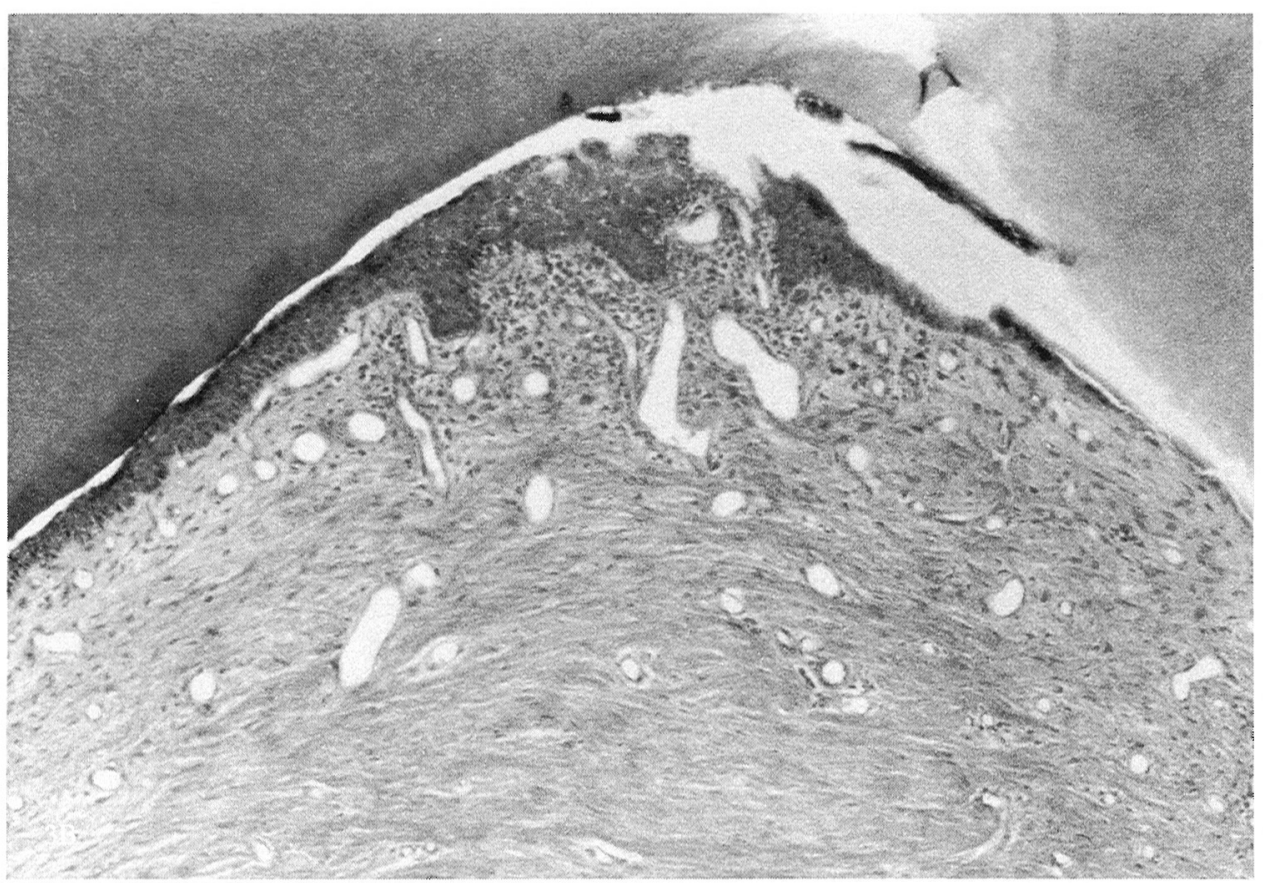

Figure 3B. Higher magnification of coronal area seen in Figure $3 A$ exhibiting an epithelialized furcation fornix. Note minimal inflammatory cell infiltration in the underlying connective tissue. (H\&E stain, original magnification $\times 100$ ).

alone. Results of the study demonstrated that: 1 ) periodontal healing following the use of the GTR procedure resulted in an increase in connective tissue and alveolar bone regeneration; and 2) adjunctive citric acid root conditioning plus autologous fibronectin application produced slightly better results, but were not statistically significant.

Previously, significantly increased amounts of connective tissue reattachment were observed 6 weeks post-surgery in the areas treated with the citric acid/fibronectin combination. ${ }^{16}$ Fibrous reattachment was enhanced at the expense of epithelial downgrowth and occurred directly to both new and old cementum and exposed dentin, often in a functional manner; i.e., perpendicular to the root surface. Areas treated with the surgery and citric acid demineralization attained moderate amounts of fibrous reattachment while areas treated with surgery only or surgery plus fibronectin were associated with a long junctional epithelium. It was concluded that the enhanced fibrous reattachment may be the product of an accelerated coalescing of exposed soft tissue and root surface collagen fibrils, while under the mediating effect of fibronectin. ${ }^{16}$

In the present study, new connective tissue reattachment and alveolar bone regeneration uncomplicated by root resorption and dentoalveolar ankylosis were seen in the roots treated by GTR procedures, both with and without citric acid conditioning and fibronectin application. This finding does not agree with previous reports, ${ }^{33,34}$ since animal studies showed that new attachment of connective tissue obtained over extended portions of the demineralized root areas were often accompanied by root resorption and ankylosis.
Pettersson and Aukhil ${ }^{33}$ examined the effects of citric acid conditioning of curetted roots on the formation of new attachment when the progenitor cells from the adjacent periodontal ligament were allowed to repopulate the wound. Results of the study indicated that new attachment could form on both acid-conditioned and non-conditioned curetted roots. However, citric acid conditioning was associated with root resorption and ankylosis. Wikesjö et al. ${ }^{34}$ examined the effects of root surface demineralization and topical fibronectin application as adjuncts to reconstructive periodontal surgery. The study showed that citric acid conditioning frequently resulted in complete connective tissue repair; however, root resorption and ankylosis were prevalent features of the healing response. The study also showed that application of fibronectin to demineralized root surfaces did not enhance the amount of connective tissue repair and did not alter the pattern of root resorption and ankylosis. The reported prevalence of root resorption and ankylosis in the above mentioned studies is at variance with findings from our previous studies, ${ }^{16,35}$ as well as the present one, since root resorption and ankylosis was not consistently observed in the periodontal healing areas.

From previous studies, it was clear that root surface demineralization with citric acid followed by autologous fibronectin application has the potential to promote periodontal healing with connective tissue reattachment to a previously diseased root. Animal studies have documented such a possibility histometrically, ${ }^{16}$ while clinical studies have also reported the possibility of beneficial results biometrically. ${ }^{35}$ The possibility exists that this approach could form reat- 


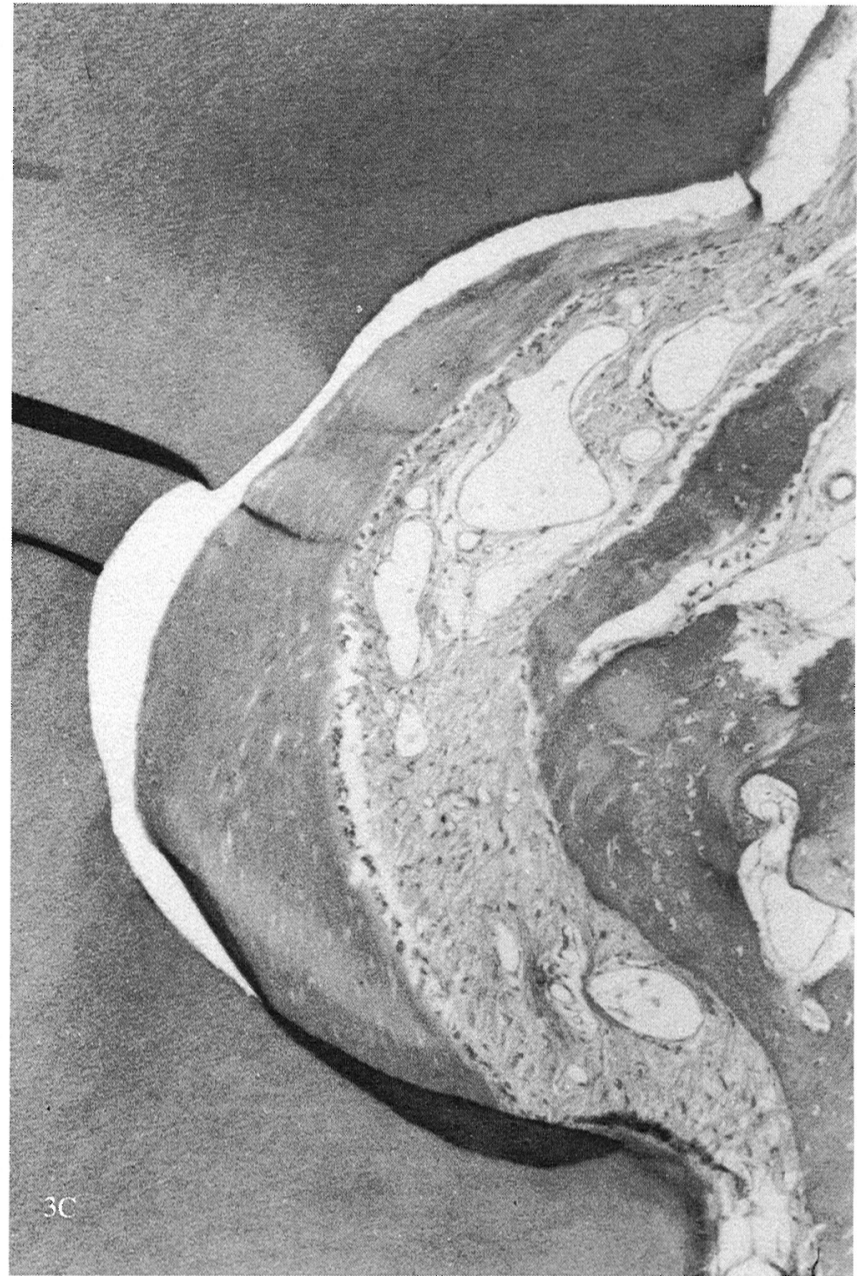

Figure 3C. Higher magnification of the right notch area in Figure $3 \mathrm{~A}$ showing significant amounts of new bone and new attachment, without evidence of ankylosis. (H\&E stain, original magnification $\times 100)$.

tachment of the gingival connective tissue to the sollagen matrix exposed on the root surface by the citric acid conditioning.

In the present study it is also clear that the effects of this approach have been masked by the overwhelming results achieved in the animal model with guided tissue regeneration. However, in spite of this, the linear and surface area measurements obtained showed slightly more positive values when the combined approach was utilized. In essence, this may mean that some benefit may arise from supplementing guided tissue regeneration. The lack of significance in the results could be due to several factors. It may be that there were too few study animals for the small differences to show significance. Nevertheless, it was decided to use $\mathrm{N}=4$ for statistical purposes. It may also be that the differences generated are so minimal that significance will never be reached. However, it may also be that GTR could benefit by adjunctive therapy, but that citric acid and fibronectin do not represent the ideal selection. When citric acid and fibronectin were first used, a very

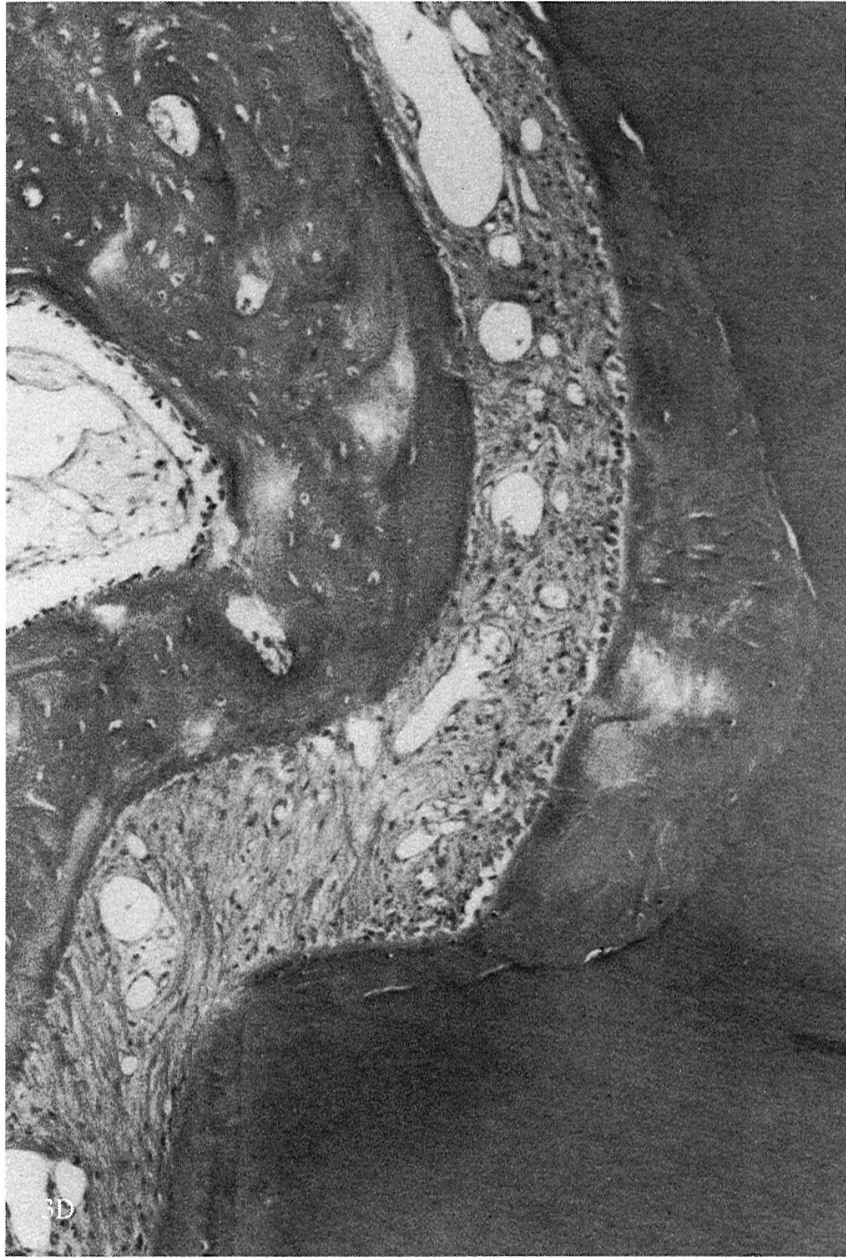

Figure $3 D$. Higher magnification of the left notch area in Figure $3 A$ showing new deposited cementum and new alveolar bone. New attachment is also evident. ( $H \& E$ stain, original magnification $\times 100)$.

minimal understanding of the chemical approach to regeneration was available. To date a series of growth factors have been described and tested in basic models, many of which certainly hold significant promise in regeneration. ${ }^{36-38}$ It may be that, in the future, a chemical approach using fibronectin or other matrix proteins, coupled to one or more growth factors could supplement the effects obtained with barrier membrane techniques.

\section{REFERENCES}

1. Kalwarf KL. Periodontal new attachment without the placement of osseous potentiating grafts. $J$ West Soc Periodont Periodont Abst 1974;22:53.

2. Dragoo MR. Regeneration of the Periodontal Attachment in Humans. Philadelphia: Lea \& Febiger; 1981:36-37.

3. Polson AM, Proye MP. Fibrin linkage: A precursor for new attachment. J Periodontol 1983;54:141.

4. Caton JG, Zander HA. The attachment between tooth and gingival tissues after periodic root planing and soft tissue curettage. $J$ Periodontol 1979;50:462.

5. Listgarten MA, Rosenberg MM. Histological study of repair follow- 
ing new attachment procedures in human periodontal lesions. $J$ Periodontol 1979;50:333.

6. Wirthlin MR, Yeager JE, Hancock EG, et al. The healing of gingival wounds in miniature swine. J Periodontol 1980;51:318.

7. Nyman S, Lindhe J, Karring T. Healing following surgical treatment and root demineralization in monkeys with periodontal disease. J Clin Periodontol 1981;8:249.

8. Stahl SS, Froum SJ, Kushner L. Periodontal healing following open debridement flap procedures. II. Histologic observations. $J$ Periodontol 1982;53:15.

9. Baumont RH, O'Leary TJ, Kafrawy AH. Relative resistance of long junctional epithelial adhesions and connective tissue attachments to plaque-induced inflammation. J Periodontol 1984;55:213.

10. Hiatt WH, Stallard RE, Butler ED, et al. Repair following mucoperiosteal flap surgery with full gingival retention. J Periodontol 1968;39:11.

11. Caffesse RG. Longitudinal evaluation of periodontal surgery. Dent Clin North Am 1980;24:751.

12. Listgarten MA, Rosenberg A, Lerner S. Progressive replacement of epithelial attachment by a connective tissue junction after experimental periodontal surgery in rats. $J$ Periodontol 1982;53:659.

13. Magnusson I, Runstad L, Nyman S, et al. A long junctional epithelium: A locus minoris resistentiae in plaque infection? J.Clin Periodontol 1983;10:333.

14. Nyman S, Ericsson I, Runstad L, et al. The significance of alveolar bone in periodontal disease: An experimental study in the dog. $J$ Periodont Res 1984;19:520.

15. Polson AM, Frederick GT. Cell processes in dentin tubules during early phases of attachment to demineralized periodontitis-affected surfaces. J Clin Periodontol 1985;12:162.

16. Caffesse RG, Holden MJ, Kon S, Nasjleti CE. The effects of citric acid and fibronectin application on healing following surgical treatment of naturally occurring periodontal disease in beagle dogs. J Clin Periodontol 1985; 12:578.

17. Caffesse RG, Smith BA, Castelli WA, Nasjleti CE. New attachment achieved by guided tissue regeneration in beagle dogs. $J$ Periodontol 1988;59:589.

18. Caffesse RG, Dominguez LE, Nasjleti CE, et al. Furcation defects in dogs treated by guided tissue regeneration (GTR). $J$ Periodontol 1990;61:45.

19. Gottlow J, Nyman S. Lindhe J. et al. New attachment formation in the human periodontium by guided tissue regeneration. Case reports. $J$ Clin Periodontol 1986;13:604.

20. Becker W, Becker BE, Berg L, et al. New attachment after treatment with root isolation procedures: Report for treated class III and class II furcations and vertical osseous defects. Int $J$ Periodontics Restorative Dent 1988;8(3):9.

21. Pontoriero R, Lindhe J, Nyman S., et al. Guided tissue regeneration in degree II furcation-involved mandibular molars. A clinical study. J Clin Periodontol 1988;15:247.

22. Smith BA, Caffesse RG, Nasjleti CE, et al. Effects of citric acid and fibronectin and laminin application in treating periodontitis. $J$ Clin Periodontol 1987;14:396.

23. Nyman S, Gottlow J, Karring T, Lindhe J. The regenerative potential of the periodontal ligament. An experimental study in monkeys. $J$ Clin Periodontol 1982;9:257.

24. Nyman S. Lindhe J. Karring T, Rylander $\mathrm{H}$. New attachment following surgical treatment of human periodontal disease. J Clin Periodontol 1982;9:290.

25. Magnusson I, Nyman S, Karring T, Egelberg J. Connective tissue attachment formation following exclusion of gingival connective tissue and epithelium during healing. $J$ Periodont Res 1985;20:201.

26. Aukhil I, Pettersson E, Suggs C. Guided tissue regeneration. An experimental procedure in beagle dogs. $J$ Periodontol 1986;57:727.

27. Blumenthal NM, Sabet TY, Barrington E. Healing responses to combined collagen-decalcified bone in periodontal defects in dogs. $J$ Periodontol 1986;57:84.

28. Blumenthal NM. The effect of supracrestal tricalcium phosphate ceramic-microfibrillar collagen grafting on postsurgical soft tissue levels. J Periodontol 1988;59:18.

29. Magnusson I, Batich C, Collins BR. New attachment formation following controlled tissue regeneration using biodegradable membranes $J$ Periodontol 1988;59:1.

30. Card SJ, Caffesse RG, Smith BA, Nasjleti CE. New attachment following the use of a resorbable membrane in the treatment of periodontitis in dogs. Int J Periodontics Restorative Dent 1989;9(1):59.

31. Pitaru S, Tal H, Soldinger M, et al. Partial regeneration of periodontal tissues using collagen barriers. Initial observations in the canine. $J$ Periodontol 1988;59:380.

32. Pitaru S, Tal H, Soldinger M, Noff M. Collagen membranes prevent apical migration of epithelium and support new connective tissue attachment during periodontal wound healing in dogs. J Periodont Res $1989 ; 24: 247$

33. Pettersson EC, Aukhil I. Citric acid conditioning of roots affects guided tissue regeneration in experimental periodontal wounds. $J$ Periodont Res 1986;21:543.

34. Wikesjö UME, Claffey N, Christersson LA, et al. Repair of periodontal furcation defects in beagle dogs following reconstructive surgery including root surface demineralization with tetracycline hydrochloride and topical fibronectin application. J Clin Periodontol 1988;15:73.

35. Caffesse RG, Kerry GJ, Chaves ES, et al. Clinical evaluation of the use of citric acid and autologous fibronectin in periodontal surgery. $J$ Periodontol 1988;59:565.

36. Terranova VP, Wikesjö UME. Extracellular matrices and polypeptide growth factors as mediators of functions of cells of the periodontium. J Periodontol 1987;58:371.

37. Terranova VP, Odziemiec C, Tweden KS, Spadone DP. Repopulation of dentin surfaces by periodontal ligament cells and endothelial cells. Effect of basic fibroblast growth factor. J Periodontol 1989;60:293.

38. Lynch SE, Williams RC, Polson AM, et al. A combination of plateletderived and insulin-like growth factors enhances periodontal regeneration. J Clin Periodontol 1989;16:545.

Send reprint requests to: Dr. Raul G. Caffesse, Department of Periodontics, Dental Branch, The University of Texas at Houston, 6516 John Freeman Ave., Houston, TX 77030.

Accepted for publication June 18, 1990. 